\title{
Research on student management method based on practice in Colleges and Universities
}

\author{
Yuan Huang ${ }^{1,2, a}$, Guo-Ping Wang ${ }^{2, b, *}$ \\ ${ }^{1}$ Xi'an University of Technology, Xi'an, 710048, China \\ ${ }^{2}$ the High-Tech College of Xi'an University of Technology, Xi'an, 710109, China \\ a541347357@qq.com, b diaphragmcoupling@163.com \\ ${ }^{\star}$ Corresponding author
}

Keywords: Student management, Working environment, Six dimensions

\begin{abstract}
Starting from the concrete practice of student management in Colleges and universities and combining with the six most common working environments in student work, this paper expounds how to guide students to think independently and develop independently in these practical management scenarios.
\end{abstract}

\section{Introduction}

Higher education is the cornerstone for a person to enter the society. The purpose of higher education is to cultivate the available talents of the society [1,2]. The cultivation of college students is mainly carried out from six aspects: social development, physical development, intellectual development, career development, emotional development and spiritual development. The orderly development of college students in these six aspects can not be separated from the realistic environment of the colleges, families and society where they live. Colleges and universities should start from the students' own development and do a good job in the environment design of the specific training in the environment they see, touch and think about every day. The management of school students should start from six environmental dimensions, such as classroom, dormitory, counselor, student organization, network and family. Through multi-level and multi-faceted guidance and training, we can create qualified college students with independent thinking, conscious learning and social responsibility.

\section{Six scenarios and the management methods}

\subsection{Classroom - the primary position of doing well the work of university students.}

College student management is an all-round management, not a department, some people's thing, but all departments of the university; all personnel work together and coordinate the results [3]. Classroom is the first position to do a good job in student work. The 21st century is the era of knowledge explosion. Traditional cramming education cannot meet the needs of modern students. With the rapid development of information technology and network technology, all knowledge can be found on the Internet. Now the characteristics of students have been inseparable from the "three screens" and the Internet era. Even if the three screens are mobile phone screens, computer screens, television screens, university education is not a simple era of knowledge transmission, learning to do problems, but to teach. The age of how students discover problems and find solutions requires that university education should not only require teachers to explain knowledge points according to their textbooks, but also innovate teaching methods, arouse students' interest in learning, cultivate students' spirit of exploring truth, cultivate students' social skills and solve problems in a subtle way. One is to pay attention to the diversity of the classroom, teaching can be in the classroom, can also be in the mountains and rivers, can be a separate explanation, can also be explored with students, of course, this requires teachers to do homework in advance, prepared, the focus is not only to teach 
students what knowledge, but also to teach students to discover. Questions, how to think independently, find solutions to problems, when a student has the ability to think independently, knowledge can be obsolete, and the ability to think independently will never be obsolete. Second, combining with the characteristics of modern students to set up online education, through the "three screens", students can learn at anytime and anywhere, that is, can make use of the spare time of students, that is, to increase the interest of learning, and at the same time can make quality education to be shared, making learning without boundaries; third, to do a good job of Inter-school results sharing. Each school has its own advantages and disadvantages, and has different high-quality teaching resources, so that students can share these resources, share the humanities and culture of different colleges and universities, and appreciate the customs and habits of different regions, which is of great benefit to the growth of students. Fourthly, teachers' training, students' growth and management, not only student management departments and The affairs of student administrators, but the major affairs of all departments and personnel in Colleges and universities, especially the words and deeds of teachers and teachers, have a direct impact on students' world outlook, outlook on life and values, and this impact is latent and long-term. Therefore, adherence to long-term teacher ethics training is to do a good job in students' ideological work.

\subsection{Dormitory - living classroom in life}

Student dormitory is the place where students communicate most frequently and closely [4]. The center of student management should be dormitory, which can achieve the trinity of education, management and service. Academic management, which is popular in foreign countries, brings life into full play. Through teachers and brothers, young people of different ages, majors, habits and regions can live together, so as to inherit and carry forward the school's cultural concepts and make college students in the long life subtle. Accepting edification will influence the students of one session and cultivate students with unique temperament. At the same time of students' self-management, we should also emphasize the dormitory management system, such as work and rest system, visitor management system, dormitory health system, and so on. At the same time, we should also emphasize individualization and give full play to students' self-management. The management of students' dormitories should be both serious and interesting, such as hosting dormitory beautification contest, Wei. Student competition, dormitory debate and so on. The dormitory is also the easiest place to establish humanistic culture and cultivate students' habits. Putting the library, discussion room, self-study room and open network in the dormitory not only makes it convenient and fast, but also cultivates students' spirit of unity, friendship and independent study, which will enable students to spend a good time in youth here.

\subsection{Counselor - student mentor}

Counselors are the easiest and most direct teachers for students. Counselors in Colleges and universities play a variety of roles in the management work[5]. They take on the roles of parents taking care of students' lives, teachers guiding students to learn, and psychologists solving students' psychological problems. There is a widespread problem of attaching importance to teachers rather than assistants. Counselors' posts are generally ignored. Counselors play an important role in the stability of colleges and universities, psychological counseling of students, student life management and other aspects. Counselors' work is complicated in nature, heavy in tasks, uncertain in future, and work treatment can not keep up with the reality. As a result, the mobility of counselors is large and the staff are unstable. To do a good job of counselors, first of all, we should start with the professionalization of counselors and establish a promotion mechanism suitable for the actual situation of counselors, such as: graded management of counselors, different levels of counselors pay, treatment, promotion are different, so that counselors have a clear prospect, stabilize the counselors team, and then do a good job of counselors. Thirdly, the introduction mechanism of high-level counselors should be formulated to attract high-level personnel into the counselors' team, and counselors should not be allowed to become a springboard for choosing jobs. 


\subsection{Student organizations - the most active activity platform for students}

Student associations are the best place to realize students 'self-management, self-education and self-development [6]. Students can cultivate their personality, train their own quality and cultivate their own ability through associations. Student associations are conducive to improving students' basic literacy such as cultural and political literacy, strengthening the construction of associations, and through teaching. Yu Le instills the students' ideological, cultural, knowledge and academic essence into one, so that students can be educated in activities and entertainment, cultivate their basic qualities and be conducive to their all-round development; secondly, associations are conducive to the construction of campus culture and various activities of associations, such as calligraphy, traditional Chinese painting and aviation. The activities of society, science and Technology Agency to carry out mode, while training the learning interest of the students, and create the students' love of traditional culture and scientific atmosphere, promote the communication between teachers and students and emotional resonance, the better the traditional culture, campus cultural heritage, once again, is the ability to exercise their own, go through community Do activities, access to different people, different things, exercise communication skills, the ability to deal with problems, independent thinking ability, make the students closer to the society, social awareness, and after graduation to work seamlessly, finally, is conducive to the stable and harmonious campus, students only correct guidance, carry out full of go. All kinds of activities are necessary to train students and stabilize the harmonious campus.

\subsection{Internet - the spiritual appetite of contemporary college students}

"Man can eat without a day, but not a day without Internet." This has become a portrayal of contemporary college students. Open, interactive, participatory unbounded network has become college students love most, students are watching the video, whenever and wherever possible brush micro-blog, WeChat chat, network education has become the new position of university students, we should pay special attention to the power of the network in the work of the students, one is the development of network education resources, network classroom network The main battlefield of network education, open classes, excellent teachers online classroom, paperless examination, answering questions on the Internet, online learning self-testing, can make learning more interesting, flexible, so that knowledge and ideas spread widely, the two is to do network information analysis, through the analysis of QQ, BBS, micro-blog, WeChat, etc [3,4]. Students Interest and positive trend, to guide the correct direction of public opinion, the three is through the network to spread positive energy, publicity, and guide the correct direction of public opinion, the four is the timely feedback, establish online response feedback mechanism to respond to student demands timely, correctly guiding the students, make students work.

\subsection{Family - the premise of doing a good job in student management}

Student management is inseparable from the support of parents. Students come from different families, have different backgrounds, living environment, learning and lifestyle. Doing a good job of students is closely related to the close cooperation of parents. Doing a good job of parents' work, focusing on communication, understanding the needs of parents, and eliminating the idea of parents' laissez-faire school management. To manage students well together, contact parents regularly at the beginning, the middle, the end of the semester and the holidays, communicate with students about their study, life and going out, keep abreast of students 'ideological trends, and work with parents to guide students' learning and growth.

\section{Summary}

This paper points out the most important six aspects of College Students' direct contact, including classroom, dormitory, counselor, community, network, family, and describes its important role in student training. Furthermore, it puts forward the methods and Strategies of dealing with the six environments in students' work, which can provide some reference for the management of College 
students. In addition, college students in the process of school learning, not only these aspects, there are many needs to pay attention to.

\section{Acknowledgements}

This research was financially supported by the research project on teaching reform of higher education in Shaanxi(Grant NO. 17BY133).

\section{References}

[1] W. Y. Jiang, Review of student management in American universities.Teacher education research, Vol. (5), pp.71-76, 1994.

[2] J. K. Liu, Reflections on Improving the Effectiveness of College Students' Educational Management in the New Situation, Medical Education Research and Practice, , Vol.25 (2), pp.201-203, 2017

[3] X. Y. Quan, Design and implementation of educational administration information system in Universities. University of Electronic Science and technology, 2010.

[4] B. Chang, Problems and Countermeasures in the Management of College Students under the New Situation, Shandong Normal University, 2007.

[5] J. Y. Sun, Student Management System and Characteristics of American Colleges and Universities, Education and Vocational, Vol. (19), pp.92-93, 2012.

[6] Y. M. Hao, C. Liang, K. Yan, The management of college students under the new situation reflections on the education and management of post-90s college students, Education and Teaching Forum, Vol. (3), pp.8-9, 2013. 